\title{
O EXER CÍCIO E A CONSTRUÇÃO DO ENSINO DA METODOLOGIA DE INVESTIGAÇÃO CIENTÍFICA EM SAÚDE COLETIVA
}

\author{
Hisako Shima* \\ Maria Josefina Leuba Salum* \\ Vilma Machado de Queiróz*
}

SHIMA, H. et al. O exercício e a construção do ensino da metodologia de investigação científica em saúde coletiva. Rev.Esc.Enf.USP, v.30, n.2, p. 320-31, ago. 1996.

Os autores apresentam e discutem a operacionalização de uma disciplina de Metodologia de Investigação Cientifica em Saúde Coletiva, ministrada para alunos da Área de Concentração de Enfermagem em Saúde Coletiva do Programa de PósGraduação em Enfermagem da USP, cujo desenvalvimento foi norteado pelo referencial do materialismo histórico e dialético.

UNITERMOS: Processo ensino-aprendizagem. Metodologia de investigação. Saude Coletiva

\section{Uma nova possibilidade de ensinar-aprender investigar}

A formação de enfermeiros na Área de Enfermagem em Saúde Coletiva em nível de Pós-Graduação strictu sensu tem sido objeto de preocupação dos docentes do Departamento de Enfermagem em Saúde Coletiva (ENS) da Escola de Enfermagem da USP (EEUSP) desde a sua criação em 1986.

S6 a partir de 1992, no entanto, é que concretizamos a implementação das disciplinas correspondentes à nossa Área de Concentração, buscando abranger conteúdos que ajudassem o aluno a aproximar-se do saber e das práticas em Saúde Coletiva, entre elas a da Enfermagem em Saúde Coletiva.

Ao lado das disciplinas teórico-práticas específicas - obrigatórias -, preocupamo-nos também em oferecer uma outra unidade disciplinar que tratasse da investigação científica em Saúde Coletiva. Partíamos do princípio de que o progressivo domínio dos con teúdos teóricos deve estar articulado à investigação * Professor Doutor do Departamento de Enfermagem em Saúde Coletiva da Escola de
Enfermagem da Universidade de São Paulo. 
e à intervenção no processo saúde-doença e nas práticas sociais de saúde, pois, como assinala WARDE (1990, p.74) "qualquer que seja o modelo a ser adotado pelos programas, a pesquisa deve estar na base de sustentação das tarefas que pretendam realizar".

Mas não era só essa a nossa preocupação. Sabe-se que o modelo funcional da enfermagem norte-americana nascido e fortalecido sob a égide do idealismo técnico-pragmático (CASTELLANOS, 1987), ainda hoje, orienta o ensino de Enfermagem no Brasil.

Não nos surpreendia, portanto, que as disciplinas de Metodologia Científica, nos cursos de Enfermagem em geral não tratassem de uma questão fundamental para compreender o percurso investigativo em Saúde Coletiva: o fato de que as realidades sociais e de saúde podem ser investigadas (e, portanto, compreendidas cientificamente) segundo diferentes concepções teórico-filosóficas.

No plano concreto da produção do saber em Enfermagem, há uma clara marca da concepção idealista de mundo. É o que observaram CASTRO et al (1985, p. 194) ao destacar a existência "de uma postura acrítica e uma influência marcante do positivismo como fundamentação teórica e metodológica", quando arrolam as principais preocupações reveladas nos estudos que avaliam a produção científica na enfermagem, nos primeiros anos da década de 80 . Não se pode porém negar o movimento da história e a possibilidade de reconstrução e reorientação de seus marcos.

Assim é que ROCHA \& SILVA (1987, p.220), analisando o processo de produção científica em Enfermagem no Brasil, identificam

influência marcante do positivismo (...), (assinalando, contudo) (...)

uma tendência emergente de propostas alternativas que buscam fundamentação teórica em outras fontes, como, por exemplo, na dialética e na fenomenologia.

Também CASTELLANOS (1988, p.40) recupera esse movimento, destacando "influências das sub-linhas históricas (...) contrapondo-se assim, fundamentalmente, ao referencial positivista de ciência", quando analisa a estrutura conceitual da enfermagem no Brasil.

Foi sobretudo na década de 80 , com a crescente utilização de metodologias ditas "qualitativas" de investigação, que essas outras possibilidades de aproximação da realidade se apresentaram no campo da pesquisa em Enfermagem.

Alguns anos antes, na década de 70, emergira a Saúde Coletiva, que tinha, como referências internas, os questionamentos da Saúde Publica, da vertente preventivista e das Ciências Sociais e, como referências externas, a influência da obra de Foucault, daqueles que rompiam com as representações da medicina convencional, usando argumentos etnologicos, históricos e demográficos, e das organizações internacionais que estimulavam caminhos alternativos no âmbito da Saúde (COSTA, 1992). 
Questionávamos, cada vez mais, a concepção positivista que, desde o início do século, domina o sistema educacional brasileiro (GADOTTI,1987) e a formação de enfermeiros. Sem dúvida, essa mesma concepção vem demarcando a forma de fazer ciência na nossa sociedade e, portanto, o conteúdo de nossa prática profissional. Na verdade, sofríamos, tardiamente, forte influência das idéias dos críticos do positivismo, a nós reveladas em cursos e encontros extra-institucionais.

Desencadeou-se, assim, no ENS um movimento que compatibilizasse o ensino e a pesquisa da assistência de enfermagem com a nova visão emergente na área de Saúde Coletiva. Utilizamos como espaços de discussão os Fóruns Internos Departamentais, os Cursos de Extensão Universitária, as Pesquisas Departamentais e os Ciclos de Seminários sobre Investigação em Saúde Coletiva.

Nessa trajetoria, desmistificamos aquele que fora o eixo da nossa formação acadêmico-científica: a idéia de que havia um só modo de produzir ciência, pautado na concepção de que a verdade está naquilo que é mensurável e, portanto, quantificável; na concepção de que leis gerais regem os processos da sociedade numa relação linear e mecânica de causa e efeito e, sobretudo, na concepção de que produzir ciência é um ato revestido de neutralidade em relação à realidade observada.

Transformados e entendendo a Enfermagem como um trabalho - e, como tal, uma das práticas sociais na área da Saúde - não nos era mais possível construir o nosso cotidiano , enquanto docentes ou enfermeiros no âmbito da Saúde Coletiva, ancorados somente nos pressupostos do positivismo.

$\mathrm{Na}$ verdade, seria mesmo contraditorio deixar que nossas atividades tivessem hegemonicamente ainda essa marca, dadas as vertentes teóricas que vinham e vêm sustentando a construção de conhecimentos e as ações estratégicas em Saúde Coletiva e que a tornam por isso mesmo singular no campo do saber em Saúde.

Passamos a conduzir as nossas atividades, entre as quais se deu a elaboração do programa e das estratégias de ensino na Área de Concentração de Enfermagem em Saúde Coletiva (PG-ENS), norteados pelo referencial materialista histórico e dialético.

Não podemos negar, contudo, que, mesmo atingidos interna e externamente por esse movimento, nós, na Enfermagem, não escapamos do que TRIVIÑOS (1989) chama de "indisciplina intelectual" e que define como uma mistura de correntes de pensamento resultante da ausência de coerência entre os suportes teóricos que orientam o trabalho.

Foi asssim que, no conjunto de disciplinas no PG-ENS, se incluiu a de Metodologia de Investigação em Saúde Coletiva (MISC), disciplina que, na verdade, se enraizava nos Ciclos de Seminários sobre Investigação em Saúde Coletiva. Na luta contra a nossa "indisciplina intelectual", esse espaço foi criado em 1990, durante as atividades do ENS para atender a necessidade de aprofundamento do corpo docente nas questões teórico-metodológicas que envolvem o trabalho de pesquisa. 
O nosso desafio era o de conduzir um programa de ensino que permitisse ao aluno analisar criticamente os diferentes referenciais teórico-metodologicos subjacentes aos processos investigativos em saúde, especialmente no âmbito da Saúde Coletiva. Para isso, seria necessário compreender as suas bases filosóficas, possibilitando o redimensionamento dos projetos de investigação por eles propostos para a conclusão do Curso de Pós-Graduação.

Mais do que um desafio, era ambição nossa romper a limitação imposta aos alunos, durante a sua vida escolar, relativas ao desenvolvimento de suas atividades de pesquisa, o que fragmentava o significado do que é a ciência, ou do que ela pode alcançar.

Especificamente na MISC, cujo desenvolvimento será objeto deste nosso trabalho, distanciamo-nos da abordagem positivista, e foi a abordagem dialética, que orientou a análise e a discussão acerca dos referenciais teórico-metodológicos já que

a primeira tenta dar conta do funcionamento da estruturação existente; a segunda está centrada sobre as possibilidades de variação e de transformaşão da consciência e da realidade sociais. (GOLDMAN, 1972, p. 40)

\section{O arcabouço da MISC: professores, alunos, objetivos, unidades de ensino.}

A disciplina MISC inscreveu-se como disciplina eletiva da Área de Concentração em Enfermagem em Saúde Coletiva - nível Mestrado, do Programa de Pós-Graduação da EEUSP. Mesmo sendo eletiva e de uma área que só oferece curso em nível de Mestrado, todos os alunos regularmente matriculados na Área de Concentração foram orientados a cursá-la. Além disso, facultamos a matrícula na disciplina a alunos de cursos em nível de Doutorado da nossa e de outras instituições.

A MISC de 8 créditos foi oferecida, pela primeira vez, no 20 . semestre de 1992, num período de 15 semanas. Do total de 96 horas, 60 foram ocupadas com aulas teóricas e seminários; as 36 restantes, cumpridas em horário extra-classe, foram destinadas a leituras e desenvolvimento do projeto de investigação.

Embora concebida no interior do grupo de docentes que coordena a Área de Concentração em Enfermagem em Saúde Coletiva, a disciplina ficou sob a responsabilidade das três autoras deste trabalho, que, como as demais, têm articulado sua participação no movimento conjunto de organização e institucionalização do ENS, dentro de um engajamento efetivo nos processos de transformação da EEUSP, no âmbito do ensino, da pesquisa e da extensão de serviços à comunidade. 
Cursaram a disciplina um total de 13 alunos (8 regularmente matriculados e 5 ouvintes), de diferentes níveis e áreas de formação acadêmica (11 enfermeiros, 1 farmacêutico e 1 assistente social, 4 dos quais em nível de Doutorado e 9 de Mestrado). Dos 13 alunos, 7 desenvolviam seu curso de pós-graduação em outras instituições que não a EEUSP; 7 atuavam na área de docência, 2 na de pesquisa e 4 exerciam atividades técnico-administrativas na área de saúde.

Levando em conta as preocupações já expostas anteriormente, a MISC teve como finalidade última: possibilitar que os alunos reconhecessem o significado da coerência teórico-metodológica no desenvolvimento de um projeto de investigação, expressa na estreita articulação entre o referencial teórico que orienta o método e/ou técnicas de aproximação da realidade e o que orienta a interpretação da realidade e as propostas de intervenção para nela intervir.

É preciso ficar claro que, em nenhum momento, foi nossa pretensão a de impor aos alunos este ou aquele referencial. Ao contrário, nossa intenção foi a de que, fixados na sua proposta original, buscassem coesão e coerência no desenvolvimento de seu projeto investigativo.

Para isso, desenvolvemos a disciplina em duas unidades. Na primeira unidade, de caráter teórico, elegemos as seguintes temáticas, desenvolvidas em 20 horas:

- Investigação científica: Por que e para que investigar? Critérios de cientificidade.

- Investigaşão científica: A aproximação da realidade pelo positivismo, pela fenomenologia e pelo materialismo histórico e dialético.

- Investigação científica em Saúde Coletiva: A vertente da Epidemiologia Clássica e da Epidemiologia Social.

As aulas referentes aos dois primeiros temas ficaram sob a responsabilidade das três docentes da MISC e o terceiro tema foi ministrado por professor convidado especialista na área.

A segunda unidade, de caráter eminentemente prático, conduzida sob a forma de seminários, foi centrada na apresentação e análise crítica dos projetos de investigação destinados à elaboração das dissertações ou teses dos próprios alunos.

Esta unidade prática desenvolveu-se em 40 horas, sendo analisados em cada sessão de 4 horas uma média de 2 projetos. Em algumas das sessões contamos com convidados com experiência de pesquisa em um referencial específico, a fim de aprofundar a discussão sobre questões teórico-práticas relativas às vertentes orientadoras dos projetos apresentados.

Sistematicamente após cada sessão, fosse ela teórica ou prática, solicitávamos a avaliação formal da classe. No encerramento do curso, os alunos analisaram a sua trajetória através da disciplina, tendo como referência o que havia sido expresso nas avaliações manifestas por docentes e alunos individualmente após cada aula. 
A análise da evolução do aprendizado dos alunos foi centrada no processo de desenvolvimento do seu projeto de investigação, avaliando-se as mudanças quantitativas e qualitativas expressas no projeto redimensionado, apresentado ao final da disciplina.

Realizando uma nova possibilidade de ensinar-aprender investigar.

Foi pensando no que dizem TUNES et al (1990, P.1153),

mudanças nas práticas de transmissão do saber que ocorrem no seio da escola requerem, necessariamente, entre outras coisas, a adoção da idéia de que ciência, tecnologia e sociedade vinculam-se e que a natureza de tal vínculo é historicamente construída nas condições sociais de vida do homem,

que elegemos como primeira temática do curso a discussão sobre Investigação científica: Por que e para que investigar? - Critérios de cientificidade.

Buscamos, sobretudo, explicitar que, enquanto uma atividade humana, a atividade científica não é e não pode ser revestida de neutralidade e objetividade.

Recuperamos, então, a historicidade do processo de produção do conhecimento, (ANDERY te al, 1988, p.17), apontando os caminhos trilhados pela ciência e, especialmente, as finalidades e interesses que cumpre quando é conduzida sob a orientação deste ou daquele referencial teórico-metodológico.

No bojo dessa discussão, trouxemos à tona a compreensão da atividade investigativa enquanto um ato político, um fenômeno de poder e um instrumento de veiculação ideológica dos grupos hegemônicos da sociedade (JAPIASSU, 1981; DEMO, 1991; SEVERINO, 1993).

Preocupávamo-nos com o papel que a Universidade assume no rol das instituições sociais, compartilhando os questionamentos de JAPIASSU (1981) de que a Ciência que a Universidade ensina - colocando uma oposição radical entre o saber objetivo (científico) e o saber subjetivo (ideológico, filosófico ou místico),considerando consensualmente o primeiro como o único científico.

Foi ainda tônica de nossa abordagem a de que não há um único caminho para se conduzir o trabalho de investigação. Insistimos, no entanto, em deixar claro que, seja qual for o referencial adotado, prevalece sempre a questão do rigor científico e da coerência metodológica, o que foi desenvolvido no interior da segunda temática: Investigação científica: $A$ aproximação da realidade pelo positivismo, pela fenomenologia e pelo materialismo histórico e dialético.

Desmitificar o dogma da unicidade em ciência infiltrado na modernidade - que, segundo JAPIASSU(1981), oculta "a ideologia cientificista sempre pronta a produzir o divórcio entre o conhecimento do mundo natural e o conhecimento 
do mundo social" - não nos desanimava; ao contrário, estimulava a continuidade do trabalho.

Grande parte de nossa tarefa na unidade tebrica já estaria cumprida, para nós, professores da MISC, se os alunos se dessem conta de que não existe apenas um modo de fazer ciência, que os métodos científicos transformam-se no tempo dependendo de interesses e necessidades de um dado momento histórico, e que é preciso ter clareza dessa realidade.

Mas levar adiante a discussão sobre a segunda temática e, sobretudo, eleger bibliografia subsidiária não foi tarefa fácil.

Permanecia uma lacuna, especialmente no plano estratégico para a sistematização do aprendizado: carecíamos de um texto que expusesse organizada, simultânea e articuladamente as bas es teórico-conceituais e o caminho metodológico das tendências positivista, fenomenologica e materialista histórica e dialética. WARDE (1990, p.69) diz mesmo que "essa discussão aparece na literatura de modo tão intrincado que merece outro espaço para ser destrinçado".

Livros publicados recentemente em nosso meio, a que já nos referimos, como os de DEMO (1985, 1991), JAPIASSU (1981), MINAYO (1991) e TRIVIÑOS (1989), foram indicações fundamentais para orientar o desenvolvimento desse conteúdo. Foi com o auxílio desses autores, dentro das nossas possibilidades e limitações, que elaboramos então um documento-síntese que tratou do assunto, certamente ainda marcado por equívocos que hoje, (re)transformados, podemos visualizar. $O$ roteiro desse documento, na verdade um quadro comparativo, foi dividido em duas partes: bases térico-conceituais e caminho metodológico. A primeira tratou dos princípios, pressupostos, limitações e possibilidades, conceito de ciência, verdade, realidade, ética e papel do pesquisador em cada referencial. A segunda abordou a questão da revisão bibliográfica e da definição do problema, hipóteses e variáveis, contornos do objeto, critérios para compor a população de estudo, tratamento dos resultados e condução da análise, também em cada referencial. Assim nasceu um instrumento pedagógico que buscou a superação das lacunas na operacionalização do percurso científico em cada referencial, decodificando o que, muitas vezes, os textos de ciência tornam hermético (QUEIROZ et al, 1992).

A análise e a discussão da segunda temática foram conduzidas no sentido de aclarar que diferentes visões de mundo subsidiam as diversas formas de abordagens científicas: direcionam não só o recorte da realidade a ser investigada mas também as formas de sua problematização, abordagem e aproximação e modos de nela intervir.

Nas nossas discussões com os alunos, observamos, ainda, que a falta de visualização clara dessas distinções tem conduzido ao ecletismo ou "indisciplina intelectual" (TRIVIÑOS ,1992), responsável pela existência de produções de pouca utilidade nas universidades brasileiras (TRIVIÑOS, 1992).

Com base no documento-síntese a que nos referimos, solicitamos aos alunos 
que, na conclusão da unidade teórica, desenvolvessem um trabalho de análise crítica de 3 monografias de Mestrado, por nós indicadas, cada uma norteada por um referencial teorico diferente entre os apontados acima. Assim, buscávamos, na articulação entre teoria e prática, desenvolver a segunda temática da unidade teórica.

Para orientar esse trabalho, elaboramos também um roteiro que auxiliasse o aluno a identificar os critérios de cientificidade expostos por DEMO (1985) (coerência, consistência, objetivação, intersubjetividade, originalidade), bem como as possibilidades que a investigação comportava no sentido de contribuir para o desenvolvimento da intervenção na realidade.

Muitos dos nossos pós-graduandos, a essa altura do curso, se declaravam perplexos e confusos, pois, durante a sua formação escolar, não lhes tinha sido dada a oportunidade de reconhecer as diferentes formas de se fazer ciência. Isso vinha confirmar os questionamentos de JAPIASSU (1981) que aponta, nas Universidades, uma formação pautada no ensino dogmatizado, não passivel de discussão e que privilegia um único saber científico objetivo.

Por outro lado, foi-lhes possível reconhecer o lugar que cada referencial téorico-metodológico pode e deve ocupar na construção de conhecimentos, especialmente em Saúde Coletiva.

A realização dessa análise foi essencial para dar maior clareza ao conteúdo teórico e, sobretudo, para dar credibilidade àquela que vinha sendo a tônica de nossas discussões: de que a atividade científica se subordina à concepção de mundo que, num determinado momento histórico, engendra a forma especifica de se fazer ciência.

LÜDKE (1988, p.62-63), destacando que

as técnicas nada mais são do que instrumento para a obtenção de dados da pesquisa, mas (que) a metodologia envolve necessariamente uma base epistemológica, (apela para o fato de que) a distinção clara entre os aspectos técnicos, metodológicos e epistemológicos da questão e sua discussão honesta só poderão ajudar no esclarecimento do caminho ainda a ser traçado (grifos nossos).

Resta-nos, ainda, comentar o desenvolvimento da terceira temática da unidade teórica - Investigação científica em Saúde Coletiva: A vertente da Epidemiologia Clássica e da Epidemiologia Social. - em que se procurou, mais uma vez, deslocar a discussão do nível abstrato para o concreto. Além disso, os alunos puderam compreender que a Saúde Coletiva tem um percurso investigativo que the é peculiar, aproximando-os da compreensão do

papel nuclear que uma Epidemiologia dignificada pela crítica promete cumprir na elaboração desse mais vasto campo de conhecimento e de práticas. (GONÇALVES, 1989, Prefácio) 
Na condução da unidade prática, a análise dos projetos individuais seguiu, por parte de docentes e alunos, a mesma trajetoria que orientou o trabalho final da unidade teórica.

Os projetos foram sempre entregues com uma semana de antecedência para viabilizar a análise por parte de todos os docentes e alunos envolvidos. Assim sendo, os seminários foram programados de forma que, num primeiro momento, o autor expusesse apenas questões complementares, não expostas no projeto original. O segundo momento do seminário centralizou-se na discussão crítica propriamente dita do projeto, conduzida pelos docentes e alunos de modo sistemático.

Dada a especificidade de cada projeto e as necessidades do aluno, a análise ora se centrou nas questões referentes às bases tebrico-conceituais, ora se centrou no caminho metodológico. Lembramos ainda uma vez, que, em alguns dos seminários, contamos com a participação de professores convidados que, ao lado dos docentes da disciplina, conduziram formalmente a análise e discussão.

Sem que tenhamos planejado, os três referenciais teóricos abordados na unidade teórica estavam explicitados no conjunto de projetos apresentados pelos alunos, o que contribuiu para a aproximação entre teoria e prática no processo de análise dos projetos.

É preciso des tacar porém que o espaço da análise e discussão dos projetos dos alunos foi ocupado, com freqüência, por discussões de forma, em detrimento da discussão de conteúdo, em vista de dificuldades de explicitação clara, lógica e articulada do pensamento, da pouca atenção às diretrizes gerais que orientam a elaboração de um plano de pesquisa. Isso revelou a necessidade de se resgatar, previamente, conhecimentos fundamentais antes de dar início a um curso com esta proposta.

Constatamos, ainda, nos projetos apresentados, mesclas de diferentes referenciais, com citação de autores e utilização de conceitos que evidenciavam contradições e incoerências, refletindo a "informação indisciplinada" que tem dominado as atividades de pesquisa, de maneira especial, nas escolas dos países denominados do Terceiro Mundo (TRIVINÕS, 1992).

Não negamos a interdisciplinariedade, nem os momentos de compreensão equivocada no processo do (re)conhecimento da ciência e que, inegavelmente, se sucedem na transformação experimentada ao longo da nossa formação. Todavia, insistimos que é preciso que o horizonte na trajetória investigativa contemple a sistematização do trabalho em ciência, sem o que ele, e, sobretudo, o desenvolvimento individual do pesquisador ficam comprometidos. Além disso, corre-se o risco de servir a interesses outros não contidos na sua concepcão teórica.

Vale ressaltar, mais uma vez, que nos preocupamos em não qualificar, em momento algum, a superioridade desta ou daquela forma de abordagem, considerando-as apenas alternativas de qualidade diferentes para a aproximação, análise e intervenção na realidade. 
Assim, buscamos realizar, além da crítica externa, uma crítica interna, que segundo define DEMO (1985), significa realizar a avaliação metodológica de um tipo de abordagem partindo "do esforço de entender a partir da abordagem em questão" (DEMO, 1985, p.57); visualizamos essa crítica interna sempre como uma tentativa, considerando a dificuldade ou quase impossibilidade de ignorar totalmente o ponto de vista já assentado em outro referencial.

No processo de discussão, não desconsideramos portanto que seria inevitável que a análise dos projetos nas linhas positivista ou fenomenológica fosse afetada pelo referencial do materialismo histórico e dialético pelo qual nos orientamos.

$\mathrm{Na}$ avaliação feita ao final da disciplina, os alunos destacaram a relevância do conteúdo tratado na unidade teórica que, no entender deles, permitiu visualizar os diversos caminhos trilhados na ciência. Essa possibilidade que a unidade tebrica criou foi, contudo, percebida pelos alunos como algo "complexo, árido, denso, difícil, penoso e pesado", especialmente porque os conhecimentos teóricos a que já haviam tido acesso eram limitados e insuficientes para compreender as particularidades entre os diferentes modos de se fazer ciência. Apontaram, porém, que, ao longo da unidade prática, essas características que imprimiam uma marca de incompreensão do conteúdo teórico foram sofrendo uma transformação em vista de um novo movimento de ampliação gradual da compreensão dos alunos acerca da atividade científica.

Não podemos deixar de destacar, finalmente na conclusão deste trabalho, a relevância do eixo teórico-filośfico de que nos valemos para conduzir o ensino da Metologia de Investigação Científica em Saúde Coletiva.

Trabalhar com o referencial do materialismo histórico e dialético, sem fazer reducionismos simplistas, significa fundamentalmente lidar com oprincípio da busca da totalidade, cercando o objeto (no caso a investigação em Saúde Coletiva) numa perspectiva histórica e compreendendo-o nas suas mediações e correlações. Assim, a evidência da transitoriedade, da dinamicidade e das contradições que se expressam na produção de conhecimento permitiram a decomposição e a recomposição do arcabouço teórico-prático que vem conformando a investigação científica em Saúde Coletiva.

Percebemos que "não obstante todos os esforços dos cientistas, a ciência jamais se apresenta como nua noção objetiva; ela aparece sempre revestida por uma ideologia (...) que, ao lado do mais superficial fanatismo pela ciência, existe realmente a maior ignorância dos fatos e dos métodos científicos, que são muito difíceis e que se tornam cada vez mais difíceis graças à progressiva especialização dos novos ramos de investigação (...) que contra esse fanatismo (...) é necessário combater com vários meios, dos quais o mais importante deverá ser um melhor conhecimento das noções científicas essenciais". (GRAMSCI, 1984, p.70,1,2) 
SHIMA. H. et al. Building up and practicing the teaching of the scientific research methodology in collective health. Rev.Esc.Enf.USP, v.30, n.2, p. 320-31, aug. 1996.

The authors present and discuss the development of a discipline of Scientific Research Methodology in Public Health, taught to students of The Nursing Concentration Area in Public Health - from the Nursing Graduation Program of São Paulo University. The discipline was based in the framework of the historical and dialectical materialism.

UNITERMS: Learning-teaching process. Research methodology. Collective health

\section{REFERÊNCIAS BIBLIOGRÁFICAS}

ANDERY, M.A. et al., 1988. Para compreender a ciência: uma perspectiva histórica, Rio de Janeiro: Espaço e Tempo.

CASTELLANOS, B.E.P., 1987. O trabalho do enfermeiro - a procura e o encontro de um caminho para o seu trabalho: da abordagem mecânico-funcionalista à pesquisa emancipatória. Tese de Doutorado, São Paulo: Escola de Enfermagem, Universidade de São Paulo.

CASTELLANOS, B.E.P., 1988. Estrutura conceitual da enfermagem brasileira. Rev.Esc.Enf.USP, v. 22, Número Especial.

CASTRO, I.B.E. et al., 1985. Dificuldades na incorporação dos resultados de pesquisa na prática da enfermagem. In: Seminário Nacional de Pesquisa em Enfermagem, 4, São Paulo, Anais, São Paulo, Associação Brasileira de Enfermagem/FINEP. p.193-242.

COSTA, N.R., 1992. Ciências sociais e saúde: consideraçres sobre o nascimento do campo da saúde coletiva no Brasil. Saúde em Debate, v. 36, p. 58-65.

DEMO, P., 1985. Metodologia científica em ciências sociais. São Paulo, Atlas.

DEMO, P., 1991. Introdução à metodologia da ciência. 2 ed. São Paulo, Atlas.

GADOTTI, M., 1983. Concepcão dialética da educaçăo: um estudo introdutório. São Paulo, Cortez.

GOLDMAN, L., 1972. A criação cultural na sociedade moderna. São Paulo, Difel.

GONÇALVES, R.B.M., 1989. Prefácio. In: Epidemiologia sem números (N., Almeida Filho), Rio de Janeiro: Campus.

GOUVEIA, A.V., 1985. Orientaçס̃es teórico-metodológicas da sociologia da educação no Brasil. Cadernos de Pesquisa, n. 55, p. 63-7 
GRAMSCI, A., 1984. A concepção dialética da educação. 5ed. Rio de Janeiro, Civilização Brasileira.

JAPIASSU, H., 1981. Questres epistemológicas. In: O problema da objetividade (H. Japiassu), pp. 67-91. Rio Grande do Sul: Imago.

LU'DKE, M., 1988. Como anda o debate sobre metodologia quantitativas na pesquisa em educação, São Paulo. Cadernos de Pesquisa, v. 64, p. 61-3.

MARTINS, J.; BICUDO, M.A.V., 1989. A pesquisa qualitativa em psicologia: fundamentos e recursos básicos, São Paulo, Moraes.

MINAYO, M.C.S., 1991. O desafio do conhecimento: pesquisa qualitativa em saúde, Rio de Janeiro, Hucitec/Abrasco.

QUEIROZ, V.M. et al., 1992. Instrumento que sistematiza generica e esquematicamente características do encaminhamento da investigação científica no positivismo, na fenomenologia e no materialismo histórico e dialético. Texto pedagógico (mimeografado), São Paulo: Departamento de Enfermagem em Saúde Coletiva, Escola de Enfermagem, Universidade de São Paulo.

ROCHA, S.M.M.; SILVA, G.B., 1987. Linhas filosóficas e ideológicas na pesquisas em enfermagem no Brasil. Rev. Bras.Enf., v. 40, p. 214-21.

SEVERINO. A.J., 1993. Metodologia do trabalho científico. São Paulo, 19ed., Cortez.

TRIVIÑOS, A.N.S., 1992. Introdução à pesquisa em ciências sociais: a pesquisa qualitativa em educação, São Paulo. Atlas.

TUNES, E. et al, 1990. (Re)pensando a educação científica no Brasil, Ciência e Cultura, v.42, p. 1149-157.

WARDE, M., 1990. O papel da pesquisa na pós-graduação em educação. Cadernos de Pesquisa, v. 73, p. $67-75$. 